\title{
E1 reposicionamiento de la burocracia sindical en el ocaso del "Proceso" (julio de 1982-diciembre de 1983)
}

\author{
Leandro Molinaro \\ (Facultad de Filosofia y Letras, UBA) - leandromolinaro@gmail.com
}

\section{Introducción}

El siguiente trabajo aborda el proceso de normalización sindical entre julio de 1982 y diciembre de 1983, durante el tramo final de la última dictadura militar. Analizamos el devenir de las antiguas conducciones gremiales que buscaban recuperar el control de sus organizaciones intervenidas por el Estado a nivel nacional, en su mayoria tras el golpe de Estado de 1976. Nos enfocamos en tres casos relevantes: la Asociación Bancaria (AB), la Unión Ferroviaria (UF) y el Sindicato de Mecánicos y Afines del Transporte Automotor (SMATA). Planteamos que en estas organizaciones el proceso de normalización sindical surgió como producto de una negociación entre las cúpulas desplazadas y el último gobierno militar. Asimismo, estos acuerdos estuvieron relacionados con la paralización de un gran número de conflictos impulsados desde las bases para enfrentar despidos, la devaluación del salario real y otras conquistas arrasadas en los tiempos del "Proceso". Desde nuestra perspectiva, la elección de estas organizaciones laborales se debe fundamentalmente a dos razones: en primer lugar, estos gremios contaban con una tradición combativa en las décadas anteriores, siendo blanco predilecto de la represión estatal durante los gobiernos peronistas y la posterior dictadura militar. La segunda razón reside en que una gran parte de los conflictos entre capital y trabajo ocurrió en estos gremios, mientras se efectuaban negociaciones entre las antiguas cúpulas gremiales y el gobierno militar por una normalización acorde a sus intereses. En términos geográficos, centramos nuestra investigación en Capital Federal y Gran Buenos Aires (GBA) debido a que en esas zonas se produjeron una vasta cantidad de medidas de fuerza que impactaron en el comportamiento de las antiguas dirigencias de estos sindicatos a nivel nacional.

La normalización sindical ya ha sido abordada en otras oportunidades

(Archivos, año IV, $\mathrm{n}^{\circ}$ 8, marzo de 2016, pp. 33-53) 
por la historiografia: Héctor Palomino (1985), Ricardo Gaudio y Horacio Domeniconi (1986), Carla Sangrilli (2010) y Luciana Zorzoli (2015) refieren a este proceso a nivel nacional, mientras que Judit Kohan (1993) describe el fin de las intervenciones militares en la región de Rosario, San Lorenzo y Villa Constitución. Todas estas obras permiten observar diferentes matices del proceso de normalización en diferentes gremios y distintas regiones del país, aunque se centran en el desenvolvimiento de las dirigencias sindicales y de la conducción estatal. ${ }^{1}$ Desde una perspectiva diferente a estos trabajos, intentamos analizar el proceso de normalización incorporando la actuación de las bases. Sostenemos que no puede entenderse el fin de las intervenciones militares de los sindicatos por fuera de la dinámica de la lucha de clases. Por lo tanto, nuestro principal objetivo reside en describir los rasgos de las disputas de los trabajadores bancarios, ferroviarios y automotrices contra las patronales y el Estado con el fin de relacionarlos con la actuación de las antiguas cúpulas gremiales en su búsqueda de retomar la conducción de estos sindicatos.

\section{Algunas consideraciones generales sobre el proceso de normalización sindical}

El movimiento obrero se opuso a lo largo de la dictadura a la ofensiva patronal y estatal llevada a cabo a partir del golpe de Estado de 1976. Como señalan entre otros autores Pablo Pozzi (2008) y Alejandro Schneider (2000), el proletariado inició esta resistencia de forma fragmentaria, desde sus lugares de trabajo. A partir de 1978 las conducciones sindicales, tanto a nivel regional como nacional, estuvieron presentes en los conflictos con el fin de institucionalizar la oposición y descontento hacia el régimen (Schneider, 2000: 239, 240). Los principales nucleamientos dirigenciales de este período fueron la Comisión Nacional de los 25 y la Comisión Nacional de Trabajo (CNT). La Comisión de los 25 se formó en marzo de 1977 y en noviembre de 1980 impulsó la refundación de la CGT encabezada por el cervecero Saúl Ubaldini (que recibiría el nombre de CGT Brasil por la calle porteña donde se encontraba su sede), contando con el apoyo de las 62 Organizaciones. Su aparición enfrentaba la expresa prohibición estatal a cualquier confederación de tercer grado, tal como quedaba establecido en la Ley 22.105 de Asociaciones Gremiales

1. Otros dos autores abordaron esta temática pero tomando sólo los primeros años del gobierno de Alfonsín: Juan Massano (2012, 2015) analiza el intento de redefinición en la relación entre Estado y organizaciones sindicales durante los primeros años del gobierno de Alfonsín; mientras que Mónica Gordillo (2013) parte de la categoría teórica "democratización sindical" para estudiar los proyectos de normalización gremial existentes durante ese mismo gobierno. 
(sancionada el 15 de noviembre de 1979). Debido a su postura crítica hacia el régimen castrense esta central era considerada por un sector de la opinión pública como el ala "combativa" del movimiento sindical. En particular, sus miembros que formaban parte de la Comisión de los 25 recibian la denominación de "ultraduros". ${ }^{2}$ Por su lado, la CNT conformó la CGT Azopardo durante el conflicto bélico en Malvinas (Godio, 1991: 345-360). Esta central mostraba un tono conciliador hacia la dictadura militar. A pesar de sus diferentes posturas, ambas confederaciones llevaron adelante en simultáneo tres huelgas generales.

La finalización de la guerra de Malvinas abrió un contexto signado por un clima de protesta social, siendo el movimiento obrero uno de sus principales protagonistas. Como intento de contención de esta conflictividad, el último gobierno militar buscó abrir canales de negociación con las conducciones sindicales. El presidente de facto, Reinaldo Bignone, quien arribó al gobierno tras la derrota militar en el Atlántico sur, carecía de consenso social para llevar a cabo una represión profunda contra el movimiento obrero como la acontecida en los años previos. Además, en los hechos, se encontraba incapacitado para aplicar la Ley de Seguridad Industrial que prohibía toda medida de fuerza. Por lo tanto, apeló a dos tácticas que involucraban a las dirigencias gremiales. La primera de ellas consistió en implantar de forma regular la llamada Ley de Conciliación Obligatoria, en especial ante conflictos impulsados por las bases que no podian o no querian ser contenidas por las dirigencias sindicales. ${ }^{3}$ Esta intervención estatal suponía un arbitraje que obligaba a las partes a retrotraerse a la situación previa al inicio de la disputa. Significaba un intento de dejar en suspenso un conflicto, dando un espacio de negociación al Ministerio de Trabajo con las dirigencias gremiales y las patronales involucradas, accediendo a que los empresarios restablecieran el funcionamiento de la empresa en litigio con sus trabajadores. ${ }^{4}$ El empleo de esta norma era parcial ya que el gobierno permitía a la

2. Como ejemplo sobre la denominación como "ultraduros" de la Comisión de los 25, véase La Nación, 21 de febrero de 1983, p. 6, y 28 de febrero de 1983, p. 6.

3. La ley de "Resolución de Conflictos Colectivos de Trabajo" fue sancionada durante el gobierno de Arturo Frondizi (Ley 14.786, 9 de enero de 1959). Más tarde fue modificada por el gobierno militar de Juan Carlos Onganía (Ley 16.936, 26 de agosto de 1966), cuyo artículo 9 disponía que si un trabajador no cumplía con el laudo estatal podia ser despedido con causa por la patronal. Durante el tercer mandato de Juan Domingo Perón fue realizada una variación a esta norma, eliminando su fecha de caducidad que originalmente tenía vigencia hasta el 31 de diciembre de 1967 (Ley 20.638, 11 de enero de 1974).

4. El primer caso donde observamos la aplicación de esta norma durante el período estudiado ocurrió en el conflicto por despidos acontecido en la empresa autopartista Di Loreto en julio de 1982. Crónica (1era. edición), 15 de julio de 1982, p. 6. 
burguesía incumplir con su parte. Por lo general, no se retornaba a la situación previa a la disputa. En este espacio ganaban importancia las agrupaciones dirigenciales de los gremios ya que eran los representantes legales de los obreros en pugna, incluso en los casos de los sindicatos intervenidos donde, en muchos casos, la conducción de la seccional o la regional (no intervenidas) actuaban como interlocutor en el Ministerio de Trabajo. Los dirigentes podian usar estos conflictos como forma de presión para obtener beneficios propios. Precisamente, la otra táctica gubernamental consistió en impulsar la normalización sindical para dar respuesta a la presión de las antiguas conducciones expulsadas de la dirección de sus gremios en la década anterior. ${ }^{5}$ A cambio de ello, el gobierno esperaba que los sectores dirigenciales aplacaran la ebullición que provenía de las bases. ${ }^{6}$ Incluso, fracciones de la clase dominante se mostraban a favor de la devolución de los sindicatos a los viejos dirigentes. Ello se evidenciaba en julio de 1982 cuando la cúpula de la Unión Industrial Argentina (UIA) solicitó al ministro de Trabajo de Bignone, Héctor Villaveirán, la normalización sindical para tener interlocutores válidos con los cuales negociar diferentes problemáticas. ${ }^{7}$

El gobierno recién llevaría a la práctica esta medida un tiempo después en una coyuntura de conflictos y anuncios de medidas de fuerza por parte de las dos centrales sindicales en septiembre de 1982. Tras un acuerdo con la dirigencia de la CGT Azopardo, que suspendió a último momento una huelga general anunciada para el 22 de ese mes, el Ministerio de Trabajo notificó que serían formadas comisiones normalizadoras en todos los sindicatos intervenidos tanto a nivel nacional como regional. ${ }^{8}$ Para ese entonces, existían 134 organismos sindicales intervenidos. En la mayoría de los casos, la formación de comisiones transitorias ahondó las luchas facciosas entre nucleamientos dirigenciales al interior de los gremios, las cuales se entrecruzaban con las disputas por espacio de poder entre la CGT Brasil y la CGT Azopardo. También tuvo repercusiones en la competencia electoral a nivel nacional entre la Unión Cívica Radical (UCR) y el Partido Justicialista (PJ). ${ }^{9}$

5. Los intentos de iniciar una normalización sindical habian comenzado tiempo atrás de forma tenue durante el gobierno del general Leopoldo Galtieri, aunque este proceso se vio interrumpido rápidamente por el desembarco militar en las Malvinas (Sangrilli, 2010: 154, 155; Zorzoli, 2015: 157).

6. No obstante, vale aclarar que este proceso no fue homogéneo. Existen indicios de experiencias en las cuales las bases sindicales tuvieron participación en las comisiones transitorias, aunque las mismas deben ser indagadas en profundidad.

7. La Nación, 14 de julio de 1982, p. 9.

8. Crónica (1era. edición), 23 de septiembre de 1982, p. 9.

9. El candidato presidencial por la UCR, Raúl Alfonsín, denunció la existencia de un supuesto pacto militar-sindical. Involucró a miembros de la jerarquía castrense con 
Estas confrontaciones en la superestructura no pueden apartarnos de nuestro objetivo de destacar la lucha de los trabajadores en algunos de los sindicatos intervenidos como factor fundamental para comprender la importancia de la normalización tanto para las antiguas cúpulas sindicales como así también para los empresarios y el gobierno castrense. A continuación intentaremos demostrar esto último en los casos de la Asociación Bancaria, la Unión Ferroviaria, y el SMATA, tres sindicatos intervenidos militarmente donde predominaba un fuerte nivel de conflictividad y una tenaz resistencia de las bases.

\section{Lucha y normalización en el sindicato bancario}

La Asociación Bancaria había sido intervenida militarmente a nivel nacional luego del golpe de Estado. Hasta la interrupción del régimen constitucional su secretario general había sido Juan Ezquerra. Luego de la intervención, la figura de Ezquerra resultó opacada por el peronista Juan José Zanola (secretario de prensa de la Bancaria hasta 1976) quien retornó al sindicato en 1977 como asesor de diferentes interventores militares. Luego de la guerra de Malvinas, las diferentes tendencias internas se volcaron a reclamar por la normalización como ocurriera en otros gremios en similar situación. Zanola tejió una alianza, el Movimiento Nacional Bancario - Lista Blanca, con trece agrupaciones que incluía representantes de la CGT Brasil y la CGT Azopardo (aunque no adhería oficialmente a ninguna de estas centrales) y diferentes nucleamientos de la UCR con presencia en el gremio (como la representada por el dirigente porteño Juan José Tejerina). Más tarde incluiría a la agrupación Sumando, representante del Partido Comunista (PC) en el gremio. ${ }^{10}$ Zanola también contaba con el apoyo de las 62 Organizaciones. Su aliado Tejerina ostentaba la máxima autoridad de la seccional Buenos Aires (Capital Federal y GBA) que contaba con la mayoría de los afiliados a la AB. ${ }^{11}$ Este frente gremial pactó con el gobierno militar la formación de una comisión transitoria normalizadora (19 de noviembre de 1982), encabezada por Zanola. ${ }^{12}$ Esta negociación no estuvo exenta de presiones y conflictos que se enraizaban con demandas de los tra-

sindicalistas peronistas con peso en la estructura partidaria del PJ como Lorenzo Miguel, Rogelio Papagno y Herminio Iglesias (La Nación, 26 de abril de 1983, p. 8).

10. El PC, en un principio, fue crítico del bloque formado por Zanola. En junio de 1983 dio un giro de 180 grados: para las elecciones nacionales del gremio se integró a la Lista Blanca. Qué Pasa, n 118, 25 de mayo de 1983, p. 9; Qué Pasa, n 123, 29 de junio de 1983, p. 6.

11. Solidaridad Socialista, $\mathrm{n}^{\circ} 36,4$ de agosto de 1983, p. 7.

12. Crónica (1era. edición), 23 de noviembre de 1982, p. 6. 
bajadores. En los dias anteriores al acuerdo, la seccional Buenos Aires impulsó reclamos en busca de recuperar conquistas perdidas en los años previos. El 5 de noviembre de 1982, "día del bancario", aproximadamente un millar de empleados se movilizaron frente al Ministerio de Trabajo para exigir una normalización democrática, la unificación del sueldo inicial en todos los bancos, la vigencia del convenio colectivo y la Ley de Estabilidad Bancaria. Esta presión sería utilizada por la dirigencia para negociar con el Poder Ejecutivo, al menos el primer punto del reclamo.

Para completar este proceso la comisión transitoria convocaría a elecciones del gremio en todo el país para julio de 1983. El armado electoral resultaba una muestra del control de la dirigencia sobre la organización sindical. Contando con la aprobación del Ministerio de Trabajo, designó una junta electoral compuesta sólo por miembros de la Lista Blanca. Ello generó críticas de las agrupaciones de izquierda presentes en el gremio, principalmente del Movimiento Al Socialismo (MAS) y el Partido Obrero (PO), ${ }^{13}$ los cuales tildaron al proceso electoral de fraudulento y llamaron a no participar de los mismos. ${ }^{14}$ Además, sólo se elegirian los miembros del Consejo Directivo (máximas autoridades del sindicato) para que, luego, este último reglamentara los comicios de las organizaciones internas de cada entidad bancaria. ${ }^{15}$ Es decir, se buscaba que las elecciones de los organismos de base fuesen dirigidas y controladas desde la cúpula.

A pesar del cronograma electoral establecido por los normalizadores, durante 1983 fueron llevadas a cabo asambleas para constituir organizaciones internas en buena parte de las entidades bancarias de Capital Federal y GBA, ${ }^{16}$ principalmente en momentos de conflictos impulsados "desde abajo". No obstante, la conducción transitoria gremial intentó intervenir en el proceso en aquellos lugares de trabajo donde las elecciones no convergian con sus intereses. ${ }^{17}$

En el mes de julio debían realizarse las elecciones pero fueron suspendidas por disputas intraburocráticas. Una disposición del poder judicial hizo lugar a una presentación realizada por Ezquerra. El diri-

13. La agrupación Política Obrera, fundada en 1964, se constituyó como Partido Obrero en diciembre de 1982.

14. Solidaridad Socialista, $\mathrm{n}^{\circ} 33,14$ de julio de 1983, p. 7 .

15. Qué Pasa, no 118, 25 de mayo de 1983, p. 9.

16. En los inicios de 1983 fueron elegidos delegados en los bancos Nación, Bank of América, Caja de Ahorro, Credicoop, INSSB, Quilmes. Qué Pasa, n 118, 25 de mayo de 1983 , p. 9.

17. Así ocurrió en el Banco Crédito Argentino y en la Caja de Ahorro en donde el MAS, en el primer caso, y el PO, en el segundo, contaban con activistas opositores a la cúpula sindical. Solidaridad Socialista, $\mathrm{n}^{\circ} 13,17$ de febrero de 1983, p. 2; Prensa Obrera, $\mathrm{n}^{\circ} 19,8$ de junio de 1983, p. 3. 
gente denunció que ex integrantes de la comisión normalizadora, luego de renunciar para poder presentarse como candidatos, habian seguido actuando administrativamente firmando cheques para desviar fondos y así financiar la campaña de la Lista Blanca. ${ }^{18} \mathrm{El}$ último secretario general del gremio paralizó lo que se convertiría en el seguro triunfo de Zanola. Diferentes tensiones se fueron acumulando: la suspensión de las elecciones, las internas en el grupo dirigencial y entre la conducción de la normalizadora y agrupaciones opositoras con presencia en algunas organizaciones de base. Todo ello sumado a los reclamos de las bases sin respuesta de las patronales (ya sean organismos estatales o privados) ni de la dirigencia de la Bancaria en una coyuntura de creciente inflación. Este coctel explosivo generaria un gran conflicto a desarrollarse entre los meses de julio y septiembre. Empleados de diferentes bancos impulsaron paros en muchos lugares de trabajo, principalmente para reclamar aumentos salariales. ${ }^{19}$ Tenemos registro que en la mayoría de las entidades en pugna estas decisiones fueron tomadas en asambleas con amplia participación donde, además, surgían delegados, en su mayoria jóvenes sin experiencia gremial y con diversas orientaciones politicas, que se agregaban a las organizaciones internas ya existentes..$^{20}$ Estas últimas funcionaban con mandato prorrogado desde los inicios del "Proceso" y en su mayoría respondian al zanolismo. En otros casos, los nuevos representantes constituyeron una estructura gremial inexistente desde el golpe de Estado de 1976. El PC calculaba que habían sido elegidos 700 nuevos delegados durante el desarrollo de esta lucha. ${ }^{21}$

La principal exigencia por aumentos salariales en diferentes bancos intentó ser canalizada por la seccional Buenos Aires. Impulsó una movilización al Ministerio de Trabajo, agregando a este reclamo la exigencia

18. La Nación, 18 de julio de 1983, p. 6.

19. Vislumbramos conflictos en las siguientes entidades: Nación, Ciudad, Ganadero, Caja de Ahorro, Crédito Argentino, Boston, Santurce, Tokyo, Shaw, de Italia y Río de la Plata, Galicia, Casa Cooperativo Limitado, Banco Europeo para América Latina (BEAL), Cooperativo de Caseros, Popular Argentino y Tornquist. También se sumaron otras provincias con la adhesión de filiales de las casas centrales porteñas y bancos provinciales como en Córdoba y Santa Fe.

20. Aunque pareció ser una consecuencia "natural" de la lucha y primaba una heterogeneidad política en los nuevos delegados, en estos conflictos tuvieron influencia las agrupaciones de izquierda con presencia minoritaria en el gremio (especialmente, el MAS y el PO), las cuales alentaban la organización de las bases para enfrentar a la patronal y, también, a la dirigencia sindical que, desde sus perspectivas, en lugar de encabezar estos reclamos, buscaba frenarlos. Prensa Obrera, $\mathrm{n}^{\circ} 2,28$ de diciembre de 1982, p. 4; Solidaridad Socialista, n 13, 17 de febrero de 1983, p. 2.

21. Qué Pasa, $\mathrm{n}^{\circ}$ 130, 17 de agosto de 1983, pp. 4, 5. 
del levantamiento de la suspensión de las elecciones gremiales. ${ }^{22}$ Como respuesta lograron que las patronales de las entidades en conflicto ofrecieran ajustes salariales, aunque en algunos casos los bancarios no estuvieron de acuerdo con la propuesta y siguieron en conflicto. Los directivos preferian ceder a los reclamos por el temor a que la lucha englobara al gremio en su totalidad. Para evitar esto último, apelaron al gobierno militar y a la dirigencia de la Bancaria. Ante esta ola de huelgas, el 29 de julio el Ministerio de Trabajo dictó la conciliación obligatoria, la cual fue acatada por la dirección de la seccional Buenos Aires. ${ }^{23}$ Este espacio de negociación presentaba beneficios tanto para las patronales como para el gobierno y la conducción gremial. Los primeros dos actores obtenían una paralización de las medidas de fuerza. La Lista Blanca podia, por un lado, aspirar a arrancarle a los militares un aumento salarial, reposicionándose frente a las bases, las cuales ejercían una fuerte presión sobre su dirigencia para que declararan una huelga nacional. Por otro, era vital para este sector predominante de la Bancaria negociar en los despachos de la cartera laboral el levantamiento de la suspensión de las elecciones. El Ministerio de Trabajo constituyó una comisión técnica consultiva en donde se discutirian los aumentos salariales entre la seccional Buenos Aires, encabezada por José Tejerina, y las patronales bancarias. Para ello, la conducción sindical llamó a un plenario compuesto por delegados con mandato prorrogado que apoyaban esta postura conciliadora, dejando afuera a los representantes bancarios elegidos durante los últimos meses. ${ }^{24}$

Si bien el arbitraje estatal paralizó en gran parte el conflicto, en algunos bancos fue desobedecido, continuando con medidas de fuerza. ${ }^{25}$ Frente a esta situación, la cúpula sindical osciló entre intimidar a delegados opositores a la Lista Blanca y desconocer, en algunos tramos, la conciliación obligatoria dictada, llamando a paros y movilizaciones. ${ }^{26} \mathrm{El}$ conflicto entró en su recta final en agosto cuando la seccional Buenos Aires terminó por definirse a favor de la oferta de aumento de haberes por parte la Asociación de Bancos Privados de Capital Argentino (ADE-

22. Crónica (1era. edición), 22 de julio de 1983, p. 6.

23. Esta seccional asumió la representación de todas las seccionales del país en este espacio de negociación salarial debido a la acefalia en la que se encontraba el sindicato por la suspensión de los comicios.

24. Crónica (1era. edición), 30 de julio de 1983, p. 7; Solidaridad Socialista, n 36, 4 de agosto de 1983 , p. 7.

25. Por ejemplo, en los bancos Ciudad, Comercial del Norte, Tokyo, Italia y Río de la Plata, Federal y Beal. Crónica (1era. edición), 2 de agosto de 1983, p. 8; Crónica (1era. edición), 4 de agosto de 1983, p. 8.

26. Crónica (1era. edición), 19 de agosto de 1983, p. 9. 
BA). Las subas acordadas sólo servían para equiparar salarialmente a los bancos más rezagados con aquellas entidades donde se habian logrado aumentos durante el conflicto. ${ }^{27}$ En uno de los plenarios donde se decidió este acuerdo no le fue permitido el acceso a los activistas y delegados opositores (de los bancos Italia y Río de la Plata, Crédito Argentino, Tornquist, Federal, Chaco y Ganadero Comercial del Norte) que querian presenciar la reunión para pedir por la continuación del plan de lucha. Estos últimos denunciaron que fueron atacados a golpes y con gas lacrimógeno para dispersarlos por sujetos que respondian a la cúpula sindical. ${ }^{28}$

Casualmente, o no tanto, mientras se ajustaban los detalles del acuerdo entre las partes en la cartera laboral, un fallo judicial de la Sala Primera de la Cámara de Apelaciones de Trabajo dejó sin efecto la suspensión de las elecciones del gremio, las cuales fueron reprogramadas para el mes de octubre. ${ }^{29}$ En los dias siguientes la dirigencia sindical comenzó una ofensiva contra los delegados elegidos durante el conflicto en algunos bancos de importancia como el Provincia (cuyo personal había sido uno de los puntales de la lucha) y el Ciudad. ${ }^{30}$ En las elecciones sólo se presentó la Lista Blanca ya que las agrupaciones opositoras decidieron abstenerse de participar en repudio a las maniobras fraudulentas establecidas por la comisión normalizadora. Zanola se consagró, así, como secretario general a nivel nacional. ${ }^{31}$

\section{La normalización sindical fragmenta la resistencia ferroviaria}

Los ferroviarios habian sufrido en carne propia las transformaciones estructurales acontecidas en el país desde mediados de la década de 1970. Entre 1976 y 1982, las medidas económicas tomadas por la dictadura provocaron la pérdida de aproximadamente 60 mil puestos de trabajo (Cena, 2009: 351; Pozzi, 2008: 42). Frente a la ofensiva estatal y patronal, este sector entabló duros enfrentamientos contra

27. Crónica (1era. edición), 31 de agosto de 1983, p. 6; "Para avanzar, hace falta una nueva dirección", Solidaridad Socialista, n 40, 1 de septiembre de 1983, p. 6.

28. Solidaridad Socialista, $\mathrm{n}^{\circ}$ 39, 25 de agosto de 1983, p. 7; Prensa Obrera, $\mathrm{n}^{\circ} 29$, 26 de agosto de 1983, p. 14.

29. Crónica (1era. edición), 8 de septiembre de 1983, p. 8; Qué Pasa, nº 132, 31 de agosto de 1983, p. 6.

30. Solidaridad Socialista, $\mathrm{n}^{\circ} 40,1$ de septiembre de 1983, p. 6; Prensa Obrera, $\mathrm{n}^{\circ}$ 30, 5 de septiembre de 1983, p. 15.

31. Crónica (1era. edición), 12 de octubre de 1983, p. 8. 
la política económica del "Proceso". ${ }^{32}$ A nivel organizacional estaban divididos en cuatro sindicatos: La Fraternidad (LF), la Asociación del Personal de Dirección de Ferrocarriles Argentinos (APDFA), Asociación de Señaleros de Ferrocarriles Argentinos (ASFA) y la Unión Ferroviaria. Esta se encontraba bajo intervención militar desde mediados de 1976. $\mathrm{Su}$ antigua conducción estaba dividida en dos agrupaciones: el sector liderado por Atilio Masciotta (quien era, a su vez, secretario general de la seccional Victoria del Ferrocarril Mitre) y la Lista Verde conducida por Lorenzo Pepe, ex secretario general del sindicato. Ambas eran de extracción peronista y adherian a la CGT Brasil. El nucleamiento liderado por Pepe, además, se alineaba con la Comisión de los 25. La participación activa de los trabajadores en los conflictos era impulsada desde las seccionales que recuperaban la tradición de resistencia con la formación de "coordinadoras interferrocarrileras", presentes en diferentes momentos de la historia del gremio. Alli participaban dirigentes y activistas de los cuatro sindicatos, tomando decisiones mediante la realización de asambleas. Para el período y región estudiados, este activismo podemos vislumbrarlo, principalmente, en estaciones y talleres de las líneas interurbanas Mitre, Roca, San Martín, Urquiza, Belgrano y Sarmiento. Una nueva encarnación de la Coordinadora surgió en febrero de 1982 en la seccional Victoria del Mitre. Poco después se unirian otras doce seccionales de la UF, formando una Mesa Nacional. En la Coordinadora confluian, principalmente miembros de esta organización gremial, también algunos secretarios de seccionales de La Fraternidad y activistas peronistas, radicales y de agrupaciones de izquierda de los cuatro sindicatos. Entre estas últimas se encontraba el PC, y, con menor presencia, el MAS, el PO, y el maoísta Partido Comunista Revolucionario (PCR), cuya denominación legal era Partido del Trabajo y del Pueblo (PTP). El mayor peso en la conducción de la Coordinadora recaía en uno de los nucleamientos de la UF, siendo Masciotta el secretario general de la misma, relegando a miembros de la Lista Verde. En cuanto a los alineamientos con las entidades de tercer grado, la Mesa Nacional de la Coordinadora apoyaba a la dirección de la CGT Brasil. Este espacio intersindical llevaría a cabo medidas de fuerza en los meses posteriores a la asunción de Bignone como presidente de facto. ${ }^{33}$

El Ministerio de Trabajo anunció la creación de una comisión transi-

32. Los ferroviarios llevaron a cabo diversas medidas de fuerza que paralizaron el transporte ferroviario en varias oportunidades entre 1977 y 1982. También formaron parte de la primera huelga general contra el "Proceso" convocada por la Comisión de los 25 (27 de abril de 1979) y de las impulsadas por la CGT Brasil (22 de julio de 1981 y 30 de marzo de 1982).

33. Crónica (1era. edición), 19 de agosto de 1982, pp. 6, 7; Crónica (1era. edición), 17 de septiembre de 1982, p. 6. 
toria normalizadora en la UF en diciembre a ser designada por el interventor militar, Jorge Facal. La conformación de la misma tardaría tres meses, por disputas al interior de la vieja conducción del sindicato. ${ }^{34}$ En marzo de 1983 se llegó a un acuerdo entre las partes y asumió una comisión normalizadora con once miembros. Contaba con cinco integrantes de la Lista Verde, otros tantos del nucleamiento de Masciotta y una presidencia provisoria que recaía en Francisco Saroglia, el cual no pertenecía a ninguna de estas agrupaciones pero terminaria aliándose al nucleamiento dirigido por Pepe. ${ }^{35}$

La normalización hirió de muerte a la Coordinadora. Miembros de la Lista Verde se alejaron de este espacio que era conducido por su principal rival interno. En marzo de 1983, ocho seccionales de la UF dirigidas por activistas de esta corriente declararon públicamente su adhesión a la comisión transitoria conjuntamente con su abandono de la Coordinadora. ${ }^{36}$ Una vez conformada de manera definitiva esta comisión, tanto los dirigentes de la Verde como los representados por Masciotta boicotearon una gran cantidad de medidas de fuerza impulsadas desde este espacio. El ejemplo que mejor ilumina este aspecto reside en el frustrado plan de lucha votado en febrero de 1983 en asamblea. La Mesa Nacional, presidida por Masciotta, lo suspendió contra la voluntad de los trabajadores, hecho inédito desde la conformación de este espacio. ${ }^{37}$ En esta coyuntura de paralización, la empresa estatal Ferrocarriles Argentinos comenzó a despedir activistas, todos ellos opositores a la Lista Verde. ${ }^{38}$ Desde el anuncio gubernamental de la creación de la comisión encargada de la reorganización de la UF, la resistencia ferroviaria no desapareció pero ya no contó con un armado intersindical que pudiera articular las luchas sectoriales. ${ }^{39}$

En la segunda parte de 1983 la constante devaluación del salario real generó un fuerte malestar en el gremio que se tradujo en asambleas realizadas en seccionales de gran activismo como Victoria del Mitre, Haedo del Sarmiento y el Kilometro 5 del Roca (Gerli). ${ }^{40}$ Esta presión de las ba-

34. Política Obrera, $\mathrm{n}^{\circ} 335,28$ de diciembre de 1982, p. 5.

35. Crónica (1era. edición), 16 de marzo de 1983, p. 7.

36. Crónica (1era. edición), 4 de marzo de 1983, 7.

37. Crónica (1era. edición), 17 de febrero de 1983, p. 6.

38. Crónica (1era. edición), 3 de marzo de 1983, p. 7; Solidaridad Socialista, $\mathrm{n}^{\circ}$ 16, 17 de marzo de 1983, p. 2.

39. Asi lo atestiguan algunas luchas encabezadas principalmente por ferroviarios de la seccional Victoria del Ferrocarril Mitre y en diferentes seccionales del Roca. La Nación, 17 de mayo de 1983, p. 1; Solidaridad Socialista, n 25, 19 de mayo de 1983, p. 2; Crónica (1era edición), 30 de junio de 1983, p. 8.

40. Crónica (1era. edición), 11 de agosto de 1983, p. 7. 
ses generó que tres de los cuatro sindicatos ferroviarios (UF, LF y ASFA) convocaran a una huelga a realizarse el 22 de agosto, siendo la primera medida de fuerza conjunta tomada desde el anuncio de normalización de la Unión Ferroviaria. Frente a la negativa de Ferrocarriles Argentinos a dar lugar a este reclamo, los dirigentes de la normalizadora lanzaron un nuevo paro para el 7 de septiembre que, finalmente, terminarian suspendiendo tras aceptar un adelanto salarial. ${ }^{41}$ Esta resolución fue desconocida por algunas seccionales de la UF, tal como ocurriera en Boulogne (Ferrocarril Belgrano) y en Haedo, donde continuaron con el plan de lucha. En represalia fueron intervenidas posteriormente por la comisión normalizadora. ${ }^{42}$

Mientras negociaban con el gobierno militar la fecha del llamado a elecciones del sindicato, los dirigentes de la comisión transitoria tenian el doble objetivo de consolidar su liderazgo en el sindicato y canalizar las luchas que, por momentos, amenazaban con escapar a su control. En Haedo fueron elegidos delegados, aunque luego la seccional sería intervenida por la normalizadora. También en el Sarmiento una lista opositora (formada por integrantes de diferentes tendencias encabezada por Carlos Marin) fue elegida en la seccional de Once. No obstante, los miembros de la normalizadora se negaron a reconocer ese resultado, impidiendo el acceso a la seccional de la agrupación triunfante. ${ }^{43}$

La comisión transitoria convocó a elecciones nacionales de la UF para fines de noviembre. Con el fin de darle un carácter restrictivo a los comicios, y así favorecer a la antigua conducción del sindicato, modificó el estatuto del sindicato. Entre otras cuestiones, los cambios estatutarios establecian que la estratégica junta electoral quedaba en manos del sector de la Lista Verde, imponiéndose sobre la agrupación de Masciotta..$^{44} \mathrm{El}$ cronograma electoral determinaba que, en primer lugar, se realizaría la elección nacional, luego las de seccionales y, finalmente, las de delegados y comisiones internas. Como ocurriera en la Bancaria, los dirigentes de la comisión pretendian tener el control definitivo de la cúpula sindical para cuando fueran realizadas las elecciones en seccionales y organizaciones de base donde tenían posibilidades de

41. Solidaridad Socialista, $\mathrm{n}^{\circ}$ 40, 1 de septiembre de 1983; Hoy Servir al Pueblo, $\mathrm{n}^{\circ} 15$, 7 al 20 de septiembre de 1983, p. 5; Solidaridad Socialista, $n^{\circ}$ 41, 8 de septiembre de 1983, p. 6; Hoy Servir al Pueblo, nº 16, 21 de septiembre al 4 de octubre de 1983, p. 5.

42. Crónica (1era. edición), 16 de septiembre de 1983, p. 7; Solidaridad Socialista, ${ }^{\circ}$ 43, 22 de septiembre de 1983 p. 2.

43. Crónica (1era. edición), 18 de noviembre de 1983, p. 10; Solidaridad Socialista, $\mathrm{n}^{\circ}$ 50, 24 de noviembre de 1983, p. 3.

44. Hoy Servir al Pueblo, $\mathrm{n}^{\circ}$ 19, 2 al 15 de noviembre de 1983, p. 4. 
ser derrotados a manos de agrupaciones opositoras. ${ }^{45} \mathrm{~A}$ pesar de estas trabas, los avales fueron reunidos por 17 listas (que conformaron diversos frentes), aunque muchas de ellas estuvieron imposibilitadas de presentarse en todas las seccionales. ${ }^{46}$

Días antes de llevarse a cabo, una orden judicial suspendió el acto electoral, medida que luego fue confirmada por el Ministerio de Trabajo. El juez del Juzgado de Trabajo de Primera Instancia $n^{\circ} 32$, Humberto Savola, aplicó la disposición de no innovar al comprobar que en la imprenta de la Unión Ferroviaria habían sido confeccionadas más boletas de la Lista Verde que de las otras 16 listas oficializadas. ${ }^{47}$ Según el PC, partido aliado a esta agrupación sindical, la denuncia había sido realizada por el dirigente radical Eduardo Paternó del Movimiento de Renovación y Cambio Ferroviario, el cual no había podido conseguir los avales para la elección. Los comunistas lanzaban la sospecha de que detrás de esta maniobra estaba el partido del presidente recientemente electo, Raúl Alfonsín. ${ }^{48}$ El impasse en que entraba el mayor sindicato ferroviario al no poder completar su normalización hacia el final de la dictadura avizoraba un nuevo frente de conflicto. El limite estatal a las elecciones que mediante el fraude aseguraban casi con seguridad el triunfo de la Lista Verde, hacía entrever que desde las filas del próximo gobierno se buscaría imponer nuevas reglas a la normalización de todos los sindicatos.

\section{Lineas paralelas: la derrota de los obreros de Volkswagen Monte Chingolo y la normalización del SMATA}

El sector automotriz sufrió duros embates durante los años dictatoriales, tanto por los cambios en el sistema de producción a nivel internacional como por la situación de recesión y estancamiento que existía en el país. Algunas publicaciones de la época señalaban que

45. Crónica (1era. edición), 13 de octubre de 1983, p. 6; Prensa Obrera, nº 39, 17 de noviembre de 1983, p. 8.

46. Las agrupaciones opositoras no pudieron formar un frente en común a nivel nacional para enfrentar a la Lista Verde. Con respecto a las corrientes de izquierda, el MAS y el PO presentaron listas conjuntas en la línea Sarmiento (Violeta) y en el Roca (Marrón), mientras que el PCR-PTP se integró con algunas agrupaciones peronistas opositoras a la Verde también en el Roca. El PC, por el contrario, dio apoyo a la Lista Verde. Hoy Servir al Pueblo, n ${ }^{\circ}$ 19, 2 al 15 de noviembre de 1983, p. 4; Prensa Obrera, $\mathrm{n}^{\circ}$ 39, 17 de noviembre de 1983, p. 8; Solidaridad Socialista, $\mathrm{n}^{\circ}$ 49, 17 de noviembre de 1983, p. 2.

47. Crónica (1era. edición), 18 de noviembre de 1983, p. 10.

48. Crónica (1era. edición), 19 de noviembre de 1983, p. 8; Qué pasa, n 146, 7 de diciembre de 1983, p. 12. 
entre 1976 y 1982 se redujeron a un tercio la cantidad de trabajadores en el gremio con respecto a $1975 .{ }^{49}$ Consecuentemente, los ritmos de producción se habían duplicado desde el golpe de Estado y, para 1983, los salarios de las automotrices en Argentina era en promedio de 100 dólares, un $50 \%$ por debajo a los haberes en México y Brasil. ${ }^{50}$ No obstante esta situación y a pesar de la gran represión de los años previos, existía una rica tradición de lucha en los lugares de trabajo que había perdurado. Para principios de los años 80, observamos una oposición de los mecánicos a la ofensiva de la burguesía, con diferentes matices según la empresa. ${ }^{51}$

El SMATA, la principal organización sindical de los mecánicos, se encontraba intervenido a nivel nacional desde el golpe de Estado. La antigua conducción controlaba el gremio a nivel regional y pujaba por una normalización que le permitiese recuperar la secretaría nacional. A comienzos de 1983, los principales dirigentes se dividian en una serie de corrientes internas: el Movimiento Nacional de Unidad Automotriz Lista Verde cuyo máximo referente era José Rodríguez, secretario general del gremio hasta 1976, que controlaba las seccionales y delegaciones de Capital Federal y GBA, y tenía representantes en la mayoría de las comisiones internas del conurbano bonaerense; la agrupación "Lealtad a Kloosterman" conducida por Rubén Cardozo (seccional Santa Fe), Elpidio Torres (seccional Córdoba) y Delfino Pérez (seccionales de Capital Federal y GBA) con gran peso en importantes regionales del país; y el Movimiento Nacional de Unidad Automotriz - Lista "22 de Mayo" que dirigia la seccional San Juan. En la puja entre las centrales obreras, José Rodríguez también pertenecía a la Comisión de los 25 y la CGT Brasil. Por el contrario Cardozo y Torres de "Lealtad a Kloosterman" formaban parte de la CGT Azopardo. Junto a estas tendencias coexistian otras vinculadas con agrupaciones de izquierda (PC, PCR-PTP, ${ }^{52}$ MAS, PO e Intransigencia y Movilización Peronista).

Si bien en el periodo estudiado hubo otros choques entre trabajadores y empresarios en diferentes empresa automotrices, una de las plantas de la empresa transnacional Volkswagen (VW) se convirtió en el

49. Qué pasa, $\mathrm{n}^{\circ}$ 92, 17 de noviembre de 1982, p. 6; Prensa Obrera, $\mathrm{n}^{\circ}$ 3, 14 de enero de 1983 , p. 4.

50. Prensa Obrera, $n^{\circ} 3,14$ de enero de 1983, p. 4.

51. Una serie de trabajos hace referencia a la resistencia de los obreros de base de la industria automotriz durante la última dictadura militar: Basualdo, 2006; Giniger, Guevara, Hernández y Rivero, 2010; Lascano Warner, 2012; Harari, Casco y Guevara, 2014.

52. Una investigación reciente realizada por Matías Rubio (2015) aborda la inserción del PCR en la planta de Ford (Zona Norte, GBA) durante el "Proceso" y los primeros años del gobierno de Alfonsín. 
escenario del conflicto más importante protagonizado por las bases del periodo: la lucha llevada a cabo por los obreros de la planta situada en Monte Chingolo (Partido de Lanús, Zona Sur del GBA) entre febrero y mayo de $1983 .{ }^{53}$ Su importancia resulta cuantitativa, dado que la planta contaba con 900 empleados, y cualitativa por el grado de organización interna y las repercusiones dentro del gremio y fuera de éste. En su dinámica podemos vislumbrar la actitud de la dirigencia y sus objetivos en un caso donde una parte de las bases no le respondia y donde existía una organización interna con presencia de activistas de izquierda. A diferencia del otro establecimiento de la empresa situado en San Justo (Partido de la Matanza, Zona Oeste del GBA) donde la Lista Verde mantenía el control de la organización de base, en Monte Chingolo confluían activistas pertenecientes a la agrupación de Rodríguez con miembros de la corriente "Lealtad a Kloosterman", del PO (uno de los principales protagonistas de este conflicto fue el delegado Claudio Kohan, militante de esta organización), del PC, de Intransigencia y Movilización Peronista e independientes. Varios de ellos formaban parte de la Comisión Interna de Reclamos (CIR) y el Cuerpo de Delegados. Desde principios de la década de 1980, la posición combativa de la organización de base había impedido aumentos en los ritmos de producción y logrado las mejores remuneraciones del gremio. Para la patronal se habia vuelto prioritario desarmar la organización de base con el objetivo principal de aumentar la productividad de la empresa.

El 10 de febrero de 1983, en momentos que la mayor parte del personal se encontraba de vacaciones, la empresa decidió despedir a 175 obreros (109 de Monte Chingolo y 66 de San Justo), incluyendo a toda la CIR y cinco delegados de Chingolo, elegidos previamente pero nunca reconocidos como tales por la patronal. ${ }^{54}$ En oposición a estos despidos, la organización interna lideró una larga huelga de 21 días de duración y otras medidas de fuerza (movilizaciones y una olla popular), contando con la solidaridad de vecinos y entidades políticas, sindicales y sociales. ${ }^{55}$ Los activistas de Chingolo no sólo tuvieron que enfrentarse a la patronal, sino también al gobierno militar y a la dirigencia sindical. Principalmente, la agrupación de Rodríguez, representante legal al conducir las seccionales de Avellaneda y San Justo del SMATA, tuvo como estrategia principal intentar una salida consensuada con la empresa y el Ministerio de Trabajo. Los dirigentes desalentaron la huelga interna de Monte Chingolo desde un principio, prometiendo impulsar un paro regional de cuatro horas para el 3 de marzo. Éste no llegaria a realizar-

53. Sobre los detalles de esta lucha, véase Molinaro, 2014.

54. La Nación, 12 de febrero de 1983, p. 9.

55. Prensa Obrera, $\mathrm{n}^{\circ}$ 10, 25 de marzo de 1983, pp. 4, 5. 
se luego de que la dirigencia negociara la aplicación de la conciliación obligatoria con el Ministerio de Trabajo. La cartera laboral consiguió la suspensión del paro de las seccionales de Buenos Aires y Capital Federal pero no obligó a la empresa a volver al momento previo al estallido del conflicto. ${ }^{56} \mathrm{La}$ aplicación del arbitraje estatal, y su aceptación por los obreros en asamblea, hizo naufragar la huelga.

Tras el levantamiento de esta medida de fuerza, el desgaste producido por el largo conflicto hizo mella en los operarios de Monte Chingolo. El 3 de mayo, al finalizar el período de conciliación dictado por la cartera laboral, votaron no realizar nuevas medidas de fuerza. ${ }^{57} \mathrm{Si}$ bien durante la lucha lograron reducir la cantidad de despidos considerablemente, 27 operarios no pudieron reingresar a la empresa, entre ellos Kohan y otros delegados opositores a la Verde. ${ }^{58}$

La derrota en VW ocurría en paralelo a las negociaciones por la constitución de una comisión transitoria normalizadora en el SMATA entre el gobierno y los nucleamientos dirigenciales. Estas últimas se mostraron en contra de la resistencia activa de los obreros contra los despidos. Como mencionamos, la Lista Verde tuvo una oposición frontal a las medidas tomadas en la planta chingolense. Frente a las críticas de la organización gremial interna y de algunas agrupaciones, principalmente el PO, acusó a los activistas de pertenecer a la "ultraizquierda" y de llevar a los trabajadores a un callejón sin salida. Otra de las tácticas para desacreditar a los delegados combativos de Chingolo consistió en mostrar como exitosa la negociación llevada a cabo con la patronal y el gobierno. En publicaciones de la Lista Verde, José Rodríguez justificaba que la reincorporación de la totalidad de los trabajadores despedidos de la planta de San Justo, cuya organización de base respondía a la Verde, se debia a que los trabajadores de ese establecimiento no se habian plegado al paro por tiempo indeterminado y habian confiado la negociación a los dirigentes. Así, buscaba mostrar que la posición conciliadora de la organización interna de San Justo había sido el camino para lograr reincorporaciones, omitiendo que ello había sido producto de una concesión de la empresa para aislar a los activistas de Chingolo. ${ }^{59}$

56. Prensa Obrera, $\mathrm{n}^{\circ}$ 7, 4 de marzo de 1983, p. 12.

57. En la asamblea se hizo una primera votación a mano alzada en la que ganó la moción de continuar con la lucha. No obstante, por presión de los dirigentes de la seccional del SMATA, los trabajadores volvieron a votar, esta vez mediante urna. En esta elección ganó la postura de no realizar medidas de fuerza (350 a 250). Prensa Obrera, $\mathrm{n}^{\circ}$ 15, 6 de mayo de 1983, p. 5.

58. Crónica (1era. edición), 3 de marzo de 1983, p. 7; Solidaridad Socialista, no 23, 5 de mayo de 1983, p. 2

59. Extractos de la publicación 24 de Abril, órgano de difusión del SMATA Quilmes en: Prensa Obrera, $\mathrm{n}^{\circ} 12,15$ de abril de 1983, p. 4. 
Por su parte, activistas de "Lealtad a Kloosterman" y del PC también actuaron contra la postura más combativa. Según denunciaba el PO, habían desalentado la lucha y colaborado junto a la Lista Verde en el boicot a una fallida movilización a la sede central del SMATA decidida en asamblea. ${ }^{60}$

La oposición dirigencial a esta lucha tuvo su recompensa en las oficinas del Ministerio de Trabajo. En junio de 1983, un mes después del final del conflicto en Chingolo, el gobierno devolvió las riendas del SMATA a la antigua conducción. Los 28 cargos de la comisión normalizadora fueron repartidos entre la Lista Verde (15 cargos), "Lealtad a Kloosterman" (siete) y "22 de mayo" (seis). ${ }^{61}$ Luego de meses de negociaciones, resulta plausible argumentar que la resolución del conflicto y el rol jugado por los nucleamientos dirigenciales, principalmente la Lista Verde, contra la organización de base de VW Monte Chingolo aceleró los tiempos para concluir con la intervención militar e influyó en el reparto desigual de cargos de la comisión en favor de la agrupación de Rodríguez. Una vez que retornaron a sus sillones, los dirigentes se negaron a llamar a elecciones bajo las cláusulas de la Ley de Asociaciones Profesionales de la dictadura, decidiendo aguardar hasta que el futuro gobierno constitucional decidiese derogar dicha normativa (Sangrilli, 2010: 155). La dictadura militar en retirada no tenía la fuerza suficiente para oponerse a esta postura. No obstante, el objetivo de contener a las bases más combativas estaba cumplido en gran parte gracias a la actuación de la conducción sindical.

\section{A modo de cierre}

En el presente trabajo intentamos articular las luchas de los trabajadores en las zonas de Capital Federal y GBA de tres gremios de relevancia con la normalización sindical que benefició a dirigentes pertenecientes a las antiguas conducciones que, tras el golpe de Estado de 1976, habían conservado parte de su poder a través del control de seccionales o como colaboradores de los interventores militares. Basándonos en los casos analizados, los líderes sindicales actuaron como una capa social con intereses propios que no siempre coincidian con las aspiraciones de los trabajadores. El objetivo principal de esta burocracia residió en recuperar las riendas de los sindicatos intervenidos por los jerarcas del "Proceso". La dinámica de los conflictos en el período nos muestra que estos dirigentes intentaron canalizarlos e, incluso, desactivarlos. Esto último ocurría cuando las bases se organi-

60. Prensa Obrera, $\mathrm{n}^{\circ}$ 14, 29 de abril de 1983, p. 12.

61. Crónica (1era edición), 8 de junio de 1983, p. 7. 
zaban en abierta oposición a estos liderazgos, principalmente en sitios de trabajo donde las agrupaciones de izquierda (con excepción del PC que en los casos mencionados estaba aliado a agrupaciones dirigenciales) tenían algún grado de inserción, como observamos en la planta de VW en Monte Chingolo, algunas entidades bancarias y seccionales ferroviarias. También observamos que en las medidas de fuerza impulsadas "desde abajo", donde la participación de los trabajadores era activa y donde la burocracia sindical corría el riesgo de que escaparan a su control, las diferencias entre los nucleamientos gremiales predominantes no fueron sustanciales. Tanto las Lista Verde del SMATA como la de la UF adherian a la Comisión de los 25, este último considerado como el sector "ultraduro" de la "combativa" CGT Brasil. En los casos analizados tuvieron una postura conciliadora con el gobierno militar y abiertamente contraria a las bases que no respondian a sus posiciones. Todo ello en pos de verse beneficiados en la formación de comisiones normalizadoras en sus sindicatos.

La reconstitución de la conducción gremial a nivel nacional contaba con el apoyo de entidades patronales que, en primer lugar, buscaban un interlocutor válido y confiable. En segundo término, en momentos de conflictos, necesitaban de las dirigencias sindicales para derrotar las luchas obreras y aislar a los sectores más radicalizados. Por su parte, el Estado resultó vital en esta recuperación de espacios de la dirigencia sindical. Como vimos, el arbitraje estatal, a través de la Ley de Conciliación Obligatoria, sirvió para paralizar los conflictos, en especial en aquellos en que las bases presionaban fuertemente a sus conducciones, dando tiempo a las cúpulas gremiales para intentar una salida negociada con las patronales. Con la normalización sindical el gobierno militar saliente devolvió las riendas de los sindicatos a nivel nacional a agrupaciones que habían conducido los mismos antes del golpe de Estado de 1976 y que habian conservado su predominio a nivel regional. En una coyuntura de descomposición del régimen, la normalización sindical tuvo como efecto el encauzamiento de la alta conflictividad existente en este periodo, objetivo buscado por las patronales, el gobierno y la dirigencia de los gremios estudiados. En estos casos la burocracia sindical se sirvió de las luchas entabladas, principalmente desde los lugares de trabajo, para consolidarse a nivel institucional.

En conclusión sostenemos que los inicios de este proceso de normalización no deben entenderse sólo a partir de la negociación entre cúpulas sindicales y el Estado, sino también como consecuencia de la dinámica de la lucha entre capital y trabajo. Tras el golpe de Estado de 1976, la dirigencia gremial habia visto recortada algunas de sus atribuciones, aunque buena parte de ella había logrado acomodarse a esta 
coyuntura. ${ }^{62}$ Ahora bien, luego de la contienda bélica en Malvinas en un contexto de creciente conflictividad encabezada por el movimiento obrero, la burocracia sindical logró recuperar plenamente su rol de interlocutor tolerado por el poder político y económico en su lucha contra los explotados.

\section{Bibliografia}

Basualdo, Victoria (2006), "Complicidad patronal-militar en la última dictadura argentina: Los casos de Acindar, Astarsa, Dálmine Siderca, Ford, Ledesma y Mercedes Benz", Engranajes, revista de la Federación de Trabajadores de la Industria y Afines, $\mathrm{n}^{\circ} 5$.

Cena, Juan Carlos (2009), Ferroviarios, sinfonía de acero y lucha, Buenos Aires: Monarefa-La Nave de los Locos.

Gaudio, Ricardo y Horacio Domeniconi (1986), "Las primeras elecciones sindicales en la transición democrática", Desarrollo Económico, vol. 26, $\mathrm{n}^{\circ} 103$.

Giniger, Nuria, Sebastián Guevara, Marcelo Hernández y Cynthia Rivero (2010), "Las huellas del terrorismo de Estado sobre el movimiento obrero. Los casos de Ford y Acindar", en Claudia Figari, Paula Lenguita y Juan Montes Cató (comps.), El movimiento obrero en disputa. La organización colectiva de trabajadores, su lucha y resistencia en la Argentina del siglo XX, Buenos Aires: Ciccus, pp. 143-162.

Godio, Julio (1991), Historia del movimiento obrero argentino, 1955-1990. De la Resistencia a la encrucijada menemista, Buenos Aires: Legasa.

Gordillo, Mónica (2013), "Normalización y democratización sindical: repensando los 80", Desarrollo Económico, vol. 53, n 209-210.

Harari, Ianina, Mariano Casco y Sebastián Guevara (2014), "Conflictos obreros en la industria automotriz argentina entre 1973-1983: un análisis de la acción obrera en el lugar de trabajo antes y después del golpe militar", VII Seminario internacional de políticas de la memoria, Buenos Aires, Centro Cultural Haroldo Conti.

Kohan, Judit (1993), "El sindicalismo en el Área Metropolitana de Rosario. Intervención militar y normalización", en Judit Kohan, Elina da Fonte Pessanha, Regina Lúcia de Moraes Morel y Ricardo Antunes, Experiencias sindicales recientes. Argentina Brasil, Buenos Aires: Biblos-Fundación Simón Rodríguez.

Lascano Warner, María Florencia (2012), Cambios y continuidades en la historia de los trabajadores industriales argentinos (1973-1983). Una aproximación a través del caso de Ford Motor Argentina S.A., tesis de Maestría en Ciencias Sociales, IDES, Universidad Nacional de General Sarmiento. Massano, Juan P. (2012), Reorganización del movimiento obrero sindicalizado

62. Con relación a ello, véase el artículo de Luciana Zorzoli publicado en este dossier. 
en la posdictadura argentina. El caso de la "Ley Mucci", tesis de licenciatura, Facultad de Humanidades, Universidad Nacional de La Plata.

- (2015), "El proyecto de concertación. Sindicatos y Estado en la transición democrática”, en Alejandro Schneider y Pablo Ghigliani (comps.), Clase obrera, sindicatos y Estado. Argentina (1955-2010), Buenos Aires: Imago Mundi, pp. 173-191.

Molinaro, Leandro (2014), "Paso, paso, paso, se viene el chingolazo". Un análisis de la lucha de los obreros de la planta Volkswagen de Monte Chingolo en el ocaso de la última dictadura militar (febrero-mayo de 1983)", IV Jornadas Internacionales de Problemas Latinoamericanos.

Palomino, Héctor (1985), "El movimiento de democratización sindical". Elizabeth Jelin (comp.), Los nuevos movimientos sociales/2, Buenos Aires, CEAL, pp. 36-60.

Pozzi, Pablo (2008) [1988], Oposición obrera a la dictadura, 1976-1982, Buenos Aires: Imago Mundi.

Rubio, Matías (2015), "El retorno a la democracia y la reconstrucción de las organizaciones obreras de base. Un estudio de caso: Ford Motors Argentina (Pacheco)", VI Jornadas de la División Historia, III Taller de Historia Regional, Luján.

Sangrilli, Carla (2010), "La normalización sindical entre la dictadura y los comienzos de la democracia (1979-1984)", Estudios Sociales n 39, Santa Fe.

Schneider, Alejandro (2000), "Ladran Sancho..." Dictadura y clase obrera en la Zona Norte del Gran Buenos Aires”, en Hernán Camarero, Pablo Pozzi y Alejandro Schneider, De la Revolución Libertadora al menemismo, Buenos Aires: Imago Mundi, 203-240.

Zorzoli, Luciana (2015), "La normativa sindical entre la dictadura y el alfonsinismo, propuesta de sistematización", en Alejandro Schneider y Pablo Ghigliani (comps.), Clase obrera, sindicatos y Estado. Argentina (1955-2010), Buenos Aires: Imago Mundi, pp. 149-171.

$$
* * *
$$

Titulo: Repositioning of union bureaucracy in the fall of the "Proceso" (july 1982 - december 1983)

Resumen: El artículo aborda el devenir de las antiguas conducciones sindicales en el ocaso del denominado "Proceso de Reorganización Nacional", las cuales tenian el objetivo de recuperar el control de gremios intervenidos gubernamentalmente. Nos detenemos en tres organizaciones afectadas al proceso de normalización: Unión Ferroviaria, Asociación Bancaria y el Sindicato de Mecánicos y Afines del Transporte Automotor. Estos sindicatos tuvieron en común la participación activa de las bases en medidas de fuerza en pos de recuperar su degradado salario real y conquistas perdidas durante la dictadura. En la dinámica de estas luchas también es posible observar una misma táctica de las 
dirigencias. Siguiendo sus propios intereses como capa social, pactaron con el gobierno militar "congelar" los principales conflictos impulsados por sectores internos opositores a estas dirigencias y negociar la recuperación de las riendas del sindicato a nivel nacional.

Palabras clave: movimiento obrero - dirigencia sindical - normalización sindical - dictadura militar - lucha entre capital y trabajo.

\begin{abstract}
The article discusses about the evolution of the union pipes in the fall of the named "Proceso de Reorganizacion Nacional", which had as objective to recover the control of unions interfered by government. We emphasize in three organizations that suffered the normalization process: Unión Ferroviaria, Asociación Bancaria and Sindicato de Mecánicos y Afines del Transporte Automotor. These unions had in common the active participation of their foundations in forceful measures in order to regain their reduced real wage and social conquers that were lost during the dictatorship. Through these struggles it is also possible to watch the same tactic from the leadership of these unions. Pursuing their own interests as social layer, they agreed with the military government to "freeze" the main conflicts pushed by internal sectors that were confronted or outside the influence area of these leaderships. The most used method consisted in accepting the call to "compulsory conciliation" by the Labor Ministry when facing conflicts with active participation of the foundations and negotiating the recovery of the leads of the union at national level.
\end{abstract}

Keywords: labor movement - union leadership - union normalization - military dictatorship - struggle between capital and labor

Recepción: 6 de noviembre de 2015. Aprobación: 20 de febrero de 2016 . 